\title{
A PRIMEIRA GUERRA NO ROMANCE PICARESCO DE HANS HERBERT GRIMM SCHLUMP
}

\author{
Valéria Sabrina Pereira ${ }^{1}$
}

Resumo: Schlump (1928) relata as aventuras de um soldado durante a Primeira Guerra. Apesar de forte divulgação, Schlump teve uma recepção pobre. Em 1933, a obra foi queimada e proibida pelos nazistas. Após décadas de esquecimento, o crítico literário Volker Weidermann lançou, em 2008, um livro sobre a Queima de Livros que deu início ao processo de recuperação da obra e lhe concedeu e uma nova chance de recepção. Schlump foi relançado por ocasião do centenário da Primeira Guerra, e gozou de uma recepção positiva da crítica - marcada por um evidente desejo de compensação por sua história no Nazismo. Uma leitura mais atenta, contudo, revela uma atitude mais leviana do que pacifista, em uma narrativa que é incapaz de entregar o olhar crítico que suas elogiosas resenhas prometem, como será apresentado neste artigo.

Palavras-chave: Primeira Guerra; romance picaresco; Queima de Livros

Abstract: Schlump (1928) narrates the adventures of a soldier during the First World War. Despite its massive divulgation, Schlump had a poor reception at its time. In the year 1933, the work was forbidden and burned by the Nazis. After decades of oblivion, in 2008, the literary reviewer Volker Weidermann published a book about the Book Burning, which started a process of recuperation of the work, giving it a new chance, as it was published for the second time in the $100^{\text {th }}$ anniversary of the First World War. The reception to Schlump was very positive and showed a clear desire of the critics to compensate for what happened during the Nazi regime. A careful lecture of the book, however, reveals an attitude that tends to being more frivolous than pacifist, and a narrative that is unable to deliver the critical look that was promised by its recent positive reviews, as it will be presented in this article.

Keywords: First World War; picaresque novel; Book Burning.

1 Professora adjunta da área de Língua e Literatura Alemã na Faculdade de Letras da Universidade Federal de Minas Gerais e coordenadora pedagógica de língua alemã no Idioma sem Fronteiras da UFMG. E-mail: valeriasabrinap@gmail.com. 
Em 10 de maio de 1933, poucos meses após a ascensão de Hitler ao poder, ocorreu em Berlim, e diversas outras cidades alemãs, a Queima de Livros, um evento organizado por estudantes universitários que foi o ponto alto de ações contra o que era por eles chamado de "espírito não-alemão". Nessa noite, milhares de livros foram destruídos. O evento foi emblemático do rápido recrudescimento da ação censora do regime e da perseguição sistemática a marxistas, judeus e à oposição em geral.

A lista negra contava com livros de literatura, artes, história, ciências políticas, religião, filosofia e pedagogia. Se uma parcela dos livros queimados eram obras de autores como Karl Marx, Sigmund Freud, Thomas Mann e Erich Maria Remarque, muitos outros caíram no esquecimento após a censura. Finda a guerra, e com o passar do tempo, cresceu a curiosidade das gerações pós-guerra pelas obras que faziam parte da lista. Um primeiro resgate foi realizado por Jürgen Serke, que lançou em 1977 o livro Die verbrannten Dichter (Os escritores queimados). O então jornalista do periódico Stern fez para a revista uma série de matérias sobre autores cujas obras haviam sido queimadas, buscando também apresentar o que aconteceu com eles após a proibição dos livros. Alguns autores, ainda vivos, foram entrevistados para a posterior publicação do livro que apresentava o retrato de aproximadamente quarenta personalidades atingidas pela censura. O livro se ocupou de figuras que indubitavelmente fazem parte do cânone alemão, como Alfred Döblin, mas também apresentou figuras que, como Peter Rühmkorf (1978) colocou em sua resenha do livro, praticamente não estavam mais presentes de forma pública, como Hans Henny Jahnn. A obra teve ressonância em sua época não apenas por sua temática, mas também por voltar a atenção a autores parcialmente esquecidos.

Em 2008, o crítico literário Volker Weidermann lançou um livro sobre a mesma temática, mas almejando a totalidade de títulos. Para Das Buch der verbrannten Bücher (O livro dos livros queimados), Weidermann leu todos os livros listados para a queima de 10 de maio de 1933 - salvo raras exceções das quais não conseguiu encontrar um único exemplar. O crítico apresenta cada uma das mais de cem obras então censuradas em uma breve resenha com comentário. No prefácio, Weidermann declara que não fará nenhuma análise literária (Ibid.: 11) e que é evidente que muitas dessas obras não são obras primas (Ibid.: 10). Mas, se há uma característica que marca o livro de Weidermann, ela é o páthos, como se pode notar quando ele comenta a chegada de livros encomendados em sebos à sua casa: "E cada um desses livros é um exemplar-heroico, é um pequeno triunfo e atestado de uma resistência. Um livro que permaneceu, mesmo que ele tivesse que ter desaparecido."2 (Ibid.: 10)

Entre os livros resgatados por Weidermann está o até então anônimo Schlump (em português, algo como "vagabundo"), que narra as aventuras de um soldado impertinente na Primeira Guerra. Na resenha que Weidermann nos provém, encontramos a confirmação daquilo que nos foi prometido no prefácio: uma tônica excessivamente emocional e desprendimento de conceitos da análise literária. O romance picaresco é apresentado como "um livrinho francês de saberes da boa vida" (Ibid.: 163), enfatizando a capacidade do soldado Schlump de aproveitar da vida mesmo nas situações mais adversas. Apesar de apresentar uma história completamente inacreditável, Weidermann utiliza diferentes recursos

2 Todas as traduções foram feitas por mim, a não ser quando indicado o contrário. 
retóricos para aproximar o livro da realidade. Em um ponto, fala que se trataria de "um conto-de-fadas da realidade" (Ibid.: 163). Mais adiante, parece esquecer princípios básicos de diferenciação entre autor e narrador, mais do que isso, do distanciamento entre autor e protagonista (já que se trata de uma narrativa em terceira pessoa) e se refere ao soldado Emil Schulz, vulgo Schlump, como se este realmente fosse o autor da obra anônima (Ibid.: 163). Assim, parece garantir um envolvimento maior dos leitores de sua resenha com esse autor que provavelmente teria sido perseguido pelos nazistas após a proibição de seu romance, e conclui seu comentário de forma sonhadora: "Como seria bom saber, como ela realmente continuou. A vida de Schlump.” (Ibid.: 164) Aqui é reconhecível uma aproximação da própria resenha de Weidermann com a estrutura de contos-de-fadas alemães, que frequentemente são encerrados pela frase "E se eles ainda não morreram, então vivem até hoje", uma conclusão que oferece uma noção de veracidade para a criança que acompanha a história.

O desejo de Weidermann, contudo, foi atendido. A enteada do autor entrou em contato para revelar quem teria sido o soldado: Hans Herbert Grimm, um professor de línguas que serviu durante a Primeira Guerra. A história se torna mais interessante porque a enteada tinha em sua posse os originais do livro que haviam sido escondidos dentro da parede da casa da família durante o regime nazista. Esse primeiro contato da família com Weidermann se deu em 2012, dois anos antes do centenário do início da Primeira Guerra: um prato cheio para o mercado editorial, garantindo que Schlump ganharia sua segunda chance.

Que Schlump não tenha sido inicialmente bem sucedido se deve a mais do que a subsequente ascensão do nazismo, como se vê pela história de sua primeira recepção. O lançamento de Schlump, em 1928, envolveu grandes investimentos em propaganda (WEIDERMANN: 2014, p. 336), mas as vendas não corresponderam aos esforços empregados. Não é possível afirmar que a temática ainda era muito recente ou delicada: Schlump foi lançado em 1928, mesmo ano que Krieg (Guerra), de Ludwig Renn, e Nada de novo no front, de Erich Maria Remarque, ambos com uma excelente recepção do público. Para Grimm, que tentava compreender seu próprio fracasso, a comparação entre as obras era inevitável. Em carta para um amigo próximo, escreveu:

Do meu ponto de vista, ambos os livros não são concorrência para o Schlump quando a sensação sobre essa temática houver passado. Por ora, a necessidade de uma representação real da principal experiência de toda a nossa geração ainda encobre qualquer aspiração artística justamente sobre esse assunto. Sou da opinião de que o tempo está a favor de Schlump. Mas vai demorar mais tempo do que agrada à minha paciência. (GRIMM apud WEIDERMANN: 2014, p. 337)

Grimm está convencido de que seu romance é qualitativamente superior. Schlump teria pretensões artísticas, enquanto outras obras, mesmo que de conteúdo ficcional, são consideradas por ele como inferiores por darem um tratamento mais realista à matéria. $\mathrm{O}$ tempo que Schlump ainda deveria esperar foram aproximados 85 anos, quando, por ocasião do centenário da Primeira Guerra, o romance foi relançado pela mesma editora de Das Buch der verbrannten Bücher, Kiepenheuer \& Witsch, com um posfácio de Weidermann que pautou muito da recepção recente da obra. Se, por um lado, Grimm tinha certeza de que o 
passar do tempo estaria a favor de Schlump, por outro, ele não podia prever quais seriam os fatores que influenciariam essa recepção mais positiva. Certo é que o caráter artístico da obra não estava em jogo. Chega a ser notável que Weidermann insista na retórica do conto-de-fadas realista. Que a história de um soldado bon-vivant na Primeira Guerra seja absurda não impede que Weidermann continue a enfatizar o aspecto realista, pior, não-ficcional da história. O crítico chega a inventar o termo Doku-Märchen, algo como "conto-de-fadas documental" (WEIDERMANN: 2014, p. 338), tentando nos fazer crer que a história realmente contemplava as experiências do autor. O aspecto realista, considerado inferior por Grimm, é justamente o que Weidermann e outros resenhistas ainda procuram em obras sobre a Primeira Guerra, inclusive no próprio Schlump. Na resenha sobre o livro, o jornal Frankfurter Allgemeiner Zeitung, por exemplo, chega a falar sobre "uma representação precisa da guerra em todas as suas facetas" (SCHIMMANG: 2014). A resenha do portal Deutsche Welle afirma que o romance é "realista", mas também "surreal” e, em seguida, elogia o livro pelos "detalhes realistas" em sua descrição da guerra (KÜRTEN: 2014). As batalhas podem não ser o foco principal de Grimm, mas certamente são o foco de seus resenhistas. Mesmo a resenha da tradução para o inglês, publicada pelo The Independent, ressoa essa ideia de Weidermann, afirmando que o livro vai do "romance ao realismo" (LIU: 2015).

É evidente o interesse por uma obra redescoberta após tantos anos, mas também há o desejo por reparação. A Queima de Livros é agora uma parte integral e indissolúvel de Schlump. Nenhuma resenha é feita sem que esse dado seja comentado, ou mesmo sem apresentar a interessante biografia do autor. Contudo, tanto o enredo do livro quanto a figura particular de Hans Herbert Grimm são menos elogiosos do que o crítico quer nos fazer crer. Na introdução ao livro de Weidermann sobre os livros queimados, está uma citação do autor Joseph Roth, que afirma que o fogo "enobreceu" todas as obras naquela noite (ROTH apud WEIDERMANN: 2006, p. 11). Em sua época, isso dizia muito sobre um posicionamento contra forças opressoras insurgentes. Pensar nesses livros como um coletivo sugeria a ideia de um coro oposicionista. Se esse era um pensamento lógico na época, os esforços de proporcionar o enobrecimento do romance feitos pela crítica na atualidade parecem mais difíceis de justificar - não que faltem tentativas de fazê-lo.

É interessante notar que a maior parte das resenhas de Schlump vêm acompanhadas de tentativas de desculpar algum aspecto inapropriado. Schimmang (2014), por exemplo, alega que a representação clichê das mulheres é perdoável porque os bons costumes seriam deixados de lado durante a guerra. Já Liu (2015) mantém um posicionamento crítico nesse sentido, afirmando que "I remain sceptical of Grimm's depictions of women: any woman aged over about 30 is liable to have a face like 'old camembert' or eyes 'black as a stove door', while young beauties are idealised and some are infantilised with small breasts and described affectionately as 'little'." Por outro lado, o resenhista do Independent segue tentando justificar a problemática biografia de Grimm - não tão nobre como se poderia esperar de um autor atualmente celebrado por ser pacifista: Grimm foi filiado ao partido Nacional Socialista, o que é justificado por sua família como uma tentativa de manter seu nome incógnito. Se isso talvez tenha lhe evitado dores de cabeça durante os anos que o regime durou, posteriormente, essa foi a razão de sua ruína. Na República Democrática Alemã, Grimm 
perdeu o direito de lecionar. Em 1950, poucos dias após uma conversa com autoridades locais, Grimm se suicidou, sem que o tema do encontro jamais fosse esclarecido. Vale notar que, enquanto ele escondeu a autoria de Schlump durante o regime nazista, Grimm tentou utilizar a revelação da mesma informação para conseguir a simpatia dos socialistas - sem efeito. É difícil defender a veia pacificista do autor em vista desses fatos. Liu reconhece que esse é um aspecto problemático da obra. Como Weidermann, Liu cita Joseph Roth, mas para declarar que compreende que Roth consideraria a filiação ao partido como uma mácula imperdoável. Contudo, ele justifica uma segunda chance com o seguinte argumento: "After all, time, translation and the consecutive tragedies of the German 20th-century are what this exceptional work has travelled through to reach us." (LIU: 2015)

Mas deixemos, finalmente, que a obra fale por si. Schlump relata as experiências de um jovem, Emil Schulz, apelidado Schlump (vagabundo) devido a suas travessuras, desde sua juventude e alistamento até o final da guerra. Como apontado por Schimmang (2014), o alistamento de Schlump é marcado por ilusão. O rapaz se alista voluntariamente, sonhando tornar-se um homem estiloso de uniforme, que fuma cigarros e recebe atenção especial das moças (GRIMM: 2014, p. 13). Seus pais se opõem, sua a mãe chora. Chegando na França, devido aos seus conhecimentos de francês, Schlump é selecionado para trabalhar com questões administrativas. Assim, se estabelece em um pequeno vilarejo, onde apenas se ouvem disparos ao longe. Em um lugar onde quase não há mais homens locais, Schlump goza de uma vida idílica e da atenção das moças, que são muito solícitas e, por vezes, sinceramente apaixonadas. Como também não há muitos outros homens de patente mais alta ali estacionados, ele passa a ser responsável por decisões gerais sobre como governar o vilarejo. A expectativa em um suposto livro pacifista seria que o recruta Schlump logo cairia em si, mas o idílio dura cerca de um terço do romance. Weidermann descreve o trecho fazendo uso do seu jogo de conto-de-fadas e realismo, quase como quem deseja deixar o seu leitor zonzo para que perca as faculdades críticas e não perceba aquilo é óbvio. No posfácio, ele escreve:

Ele [Schlump] chega na França, se torna, já aos dezessete anos, soberano sobre uma pequena comunidade, os corações das moças voam em sua direção, ele tenta exercer a justiça em seu pequeno mundo. Ele exerce justiça. [...] O que está acontecendo aqui? Qual o sentido desse idílio ridículo e improvável no meio da guerra? Ou isso é a realidade? (WEIDERMANN: 2014, p. 339)

Sem se aprofundar em maiores detalhes dessa fala, a simples ideia de se exercer "justiça" sendo a força invasora é um discurso que reverbera subjugação de povos e culturas, difícil de ser adequado a um discurso dito pacifista.

Quando Schlump finalmente vai para as trincheiras, ele rapidamente é ferido, e é transferido para um local seguro: o hospital militar. Isso acontece duas vezes na narrativa, fazendo que o livro tenha uma quantidade muito limitada de descrições dos horrores da guerra. Das ditas muitas facetas da guerra aqui representadas, é possível se afirmar que os campos de batalha são uma das facetas que menos recebe atenção.

O nome completo do romance é Schlump - Geschichten und Abenteuer aus dem Leben des unbekannten Musketiers Emil Schulz, genannt "Schlump". Von ihm selbst erzählt 
(Schlump - Histórias e aventuras da vida do desconhecido mosqueteiro Emil Schulz, chamado de "Schlump". Contado por ele mesmo.). Como mencionado anteriormente, ao contrário do que esse título pode indicar, o livro é narrado em terceira pessoa, o que parece ser uma indicação do pacto a ser assumido pelos leitores: trata-se de uma narrativa ficcional. $\mathrm{O}$ título, assim como a ideia de que seria uma obra escrita pelo próprio protagonista, indicam, por outro lado, a afiliação do romance ao gênero picaresco, mais especificamente, ao romance de Jacob Christoffel von Grimmelshausen, O aventuroso Simplicissimus, ${ }^{3}$ de 1669 - a principal obra do gênero escrita em língua alemã, também relacionada a uma importante guerra, a dizer, a Guerra dos Trinta Anos.

O aventuroso Simplicissimus narra, em primeira pessoa, as aventuras e desventuras de um rapaz a partir do momento no qual ele se perde no mundo, como resultado da fuga a uma violenta pilhagem ao vilarejo no qual sua família morava. Inicialmente bobo e inocente, o jovem não conhecia o próprio nome e recebe o nome de "Simplicissimus" do eremita que o acolhe. Após a morte de seu tutor, Simplicissimus continua a sua jornada, com atividades vão de bobo da corte a comandante, de charlatão a nobre. Nas muitas voltas de sua vida, Simplicissimus passa por diferentes regiões, tem contato com os mais diversos tipos de pessoa, de forma que o romance oferece um rico retrato da sociedade à época da guerra. Apesar de oferecer uma rica representação da guerra no capítulo dedicado à batalha de Wittstock, O aventuroso Simplicissimus não é tanto uma obra sobre batalhas, mas sobre as andanças e o amadurecimento de Simplicissimus. Pode-se compreender que essa também possa ter sido a intenção de Grimm, não averiguar a questão das batalhas, mas apresentar as andanças de um homem simples em tempos de guerra. Se essa comparação pode, por um lado, servir para explicar, parcialmente, diferenças do livro de Grimm com outras obras sobre a Primeira Guerra escritas na Alemanha, por outro lado, é importante considerar a relação de Schlump com o próprio gênero picaresco.

Como outros romances picarescos, Schlump traz um protagonista que se adequa mal ao padrão social no qual está inserido, mais especificamente ele não está disposto a aceitar ordens, mas ele nunca se encontra realmente à margem como os protagonistas de diversas obras do gênero. Schlump goza do apreço de todos (exceto oficiais com hierarquia mais alta), chegando a haver uma passagem na qual é descrito como franceses lhe olhavam de forma pouco amigável, pois ainda não o conheciam (GRIMM: 2014, p. 82) - independente da guerra, sua personalidade deveria ser suficiente para encantar a todos. Ele também é, desde sempre, esperto, nunca sendo a figura intelectualmente desfavorecida da qual os leitores riem. As piadas e a graça se dão sempre à custa de terceiros.

Romances picarescos costumam apresentar o desenvolvimento de sua figura central, a tal ponto que chega a haver discussão sobre se estes se enquadrariam na classificação de romance de formação. Como Jürgen Jacobs (1983, p. 26) aponta, essa classificação é pouco (ou nada) produtiva, por não levar em consideração variações do romance picaresco, mas o fato é que um processo de amadurecimento é comum ao gênero. Simplicissimus, por exem-

3 O nome completo do romance barroco é O aventuroso Simplicissimus. Isto é: A descrição da vida de um singular vagante chamado Melchior Sternfels von Fuchshaim, onde e com que aspecto ele veio a este mundo, o que nele viu, aprendeu, experimentou e sofreu, e também por que voluntariamente o abandonou. De leitura sumamente divertida e a todos proveitosa. Dado a lume por German Schleifheim von Sulsfort. 
plo, começa sua jornada como um menino tolo, se instrui e passa por diversas experiências que fazem dele um homem sábio e, por fim, um cristão dedicado. Já no caso de Schlump não é possível observar esse desenvolvimento. Ele já é esperto no início de sua jornada e os revezes pelos quais passa não resultam em mudanças de conduta. A experiência de uma vivência traumatizante - que é aquilo que costuma impulsionar a jornada do herói em romances picaresco -, não é apenas postergada em Schlump, mas seu impacto parece ser nulo, especialmente quando comparado a outros livros, como faremos abaixo.

Como mencionado anteriormente, $O$ aventuroso Simplicissimus é iniciado pela destruição de seu vilarejo, situação na qual seu pai é torturado e as mulheres de sua família são estupradas. Ao pequeno nada resta além da fuga para destino desconhecido. Assim, ele é introduzido às agruras do que essa situação de guerra trouxe para muitos do que viveram à época. A forma como a tortura do patriarca é descrita pelo narrador revela o tamanho da tolice do narrador em sua juventude, concedendo humor a um fato trágico:

Diante de tudo aquilo, pareceu-me que somente meu knan [pai] podia ser considerado um homem de muita sorte, pois ele confessou rindo o que os outros tinham de admitir entre dores e gritos lamentosos. [...] Eles o puseram diante de uma fogueira, amarraram-no de modo a imobilizar-lhe as mãos e os pés, untaram-lhe as solas dos pés com sal umedecido e obrigaram a nossa velha cabra a lambê-lo, fazendo-lhe tantas cócegas que ele quase estourou de rir. (GRIMMELSHAUSEN: 2008, p. 26-27)

Já a experiência traumática de Schlump demora a ocorrer. Por um terço do livro, sua vivência na França é idílica. Ele também é inocente na fase inicial do livro, mas a exposição da incredulidade sobre dificuldades da guerra, quando ocorre, vem para causar o riso à custa de terceiros:

E Schlump perguntou baixo, quantas baixas eles haveriam tido. / "Atiraram na perna do cavalo branco do tenente. O tenente caiu do cavalo e arrebentou o traseiro em arame farpado" / Então Schlump teve que rir. / Mas os soldados em treinamento olharam furiosos para ele, cuspiram, e opinaram que isso já era ruim o suficiente. O tenente poderia muito bem estar morto. / Pensativo, Schlump foi para casa e não acreditou em nada do que disseram, apesar de eles não terem lhe mentido. (GRIMM: 2014, p. 70)

Ao contrário do que acontece com Simplicissimus, Schlump não está, de forma alguma, envolvido no dano descrito. O riso se justifica em grande parte pela questão da perspectiva. Sua inocência justifica a insolência diante de uma situação mais grave, mas não expõe o protagonista. Quando o acontecimento traumático finalmente ocorre, a vivência em trincheiras, isso não serve de marca para qualquer mudança de atitude. É verdade que Schlump finalmente compreende o quanto a guerra é grave e finalmente teme pela própria vida, procurando a partir de então arrumar meios de fugir às suas funções, mas isso é tudo. 
Que não há nenhuma mudança de comportamento notável é algo que está descrito no próprio livro: "Para ele, foi como se houvesse acordado de um sono profundo, pela primeira vez em sua vida, ponderou sobre si e o mundo. Por um instante, perdeu sua inocência dourada e infantil. Mas isso não durou muito." (GRIMM: 2014, p. 159-160) Schlump não desenvolve nenhuma atitude que envolva uma profunda preocupação com terceiros, 4 apenas se torna mais alerta no tocante à sua própria sobrevivência, por exemplo, procurando estender sua licença médica.

Quando está no hospital militar, Schlump faz amigos com suas histórias maravilhosas, dá escapadas para a cidade, onde continua seduzindo as mulheres locais, e aprende truques para enganar os médicos e prolongar sua estadia - considerada pelo mesmo como tediosa: Schlump aprende a esfregar o termômetro nas axilas e a simular um choque de nervos (GRIMM: 2014, p. 214). Note-se que a menção ao choque de nervos não vem para expressar o trauma real da guerra, trata-se apenas de uma tática para enganar bobos. Mesmo a mutilação de outros soldados serve como tema para diversão, como quando um enfermeiro passa carregando uma perna amputada sobre o ombro, como se fosse uma espingarda (Ibid.: 185). Esta cena poderia ser encarada como um testemunho do embrutecimento pelo qual os soldados passam na guerra, mas Schlump, do qual sabemos que sua inocência está inalterada, não reprime ou demonstra reações negativas à cena.

A passagem de Schlump pelo hospital militar é de especial interesse por possibilitar uma comparação mais aproximada com o mais famoso romance picaresco sobre a Primeira Guerra: As aventuras do bom soldado Švejk (1923) de Jaroslav Hašek. Ao contrário de Schlump, Švejk não é um jovem e belo espertalhão, mas sim um homem gordo, de meia idade, que sofre de artrite. Também Švejk sabe tirar proveito das situações adversas que lhe são impostas, como no início do livro quando é internado em um hospício pra doentes mentais devido a comentários interpretados como críticas ao governo. Švejk regozija por estar em um lugar onde o carregam no colo e dão banho, onde ele sequer precisa se limpar após fazer suas necessidades. Evidentemente, Švejk só pode aproveitar da situação que se instaura por ser um completo idiota. Ao mesmo tempo em que a sua internação revela algo sórdido sobre as instituições psiquiátricas que internavam sem critério seus pacientes, e sobre o tratamento pouco humano dispensado a esses, o alvo do riso é inegavelmente Švejk e sua falta de capacidade de compreensão, que faz com que ele tenda a interpretar as piores situações como algo positivo. Mas, no que diz respeito às tentativas de fugir à guerra simulando doenças, enquanto Schlump fala sobre esfregar o termômetro no braço, como se escapar à guerra fosse uma empreitada semelhante a enganar as tias da enfermaria da escola, os truques mencionados por internos do hospital militar de As aventuras do bom soldado Švejk contam com todo o tipo de autoviolação:

- Eu paguei mais de duzentas coroas pela minha doença - declarou seu vizinho, que parecia um trapo. - Digam o nome de qualquer veneno e não encon-

4 Mesmo a perda do próprio pai é descrita de maneira fortuita. Em poucas linhas há a informação de que o homem morreu de tifo e que Schlump pode acompanhar o enterro, tendo que retornar logo para o hospital militar. Logo em seguida, a narrativa volta a descrever a situação de saúde do próprio soldado, sem desperdiçar mais qualquer palavra com o falecimento do pai. (GRIMM: 2014, p. 212s.) 
trarão um que eu não tenha tomado. Sou um armazém ambulante de venenos. Bebi líquidos corrosivos, respirei vapores de mercúrio, mastiguei arsênico, fumei ópio, bebi tintura de ópio, coloquei morfina no sanduíche, engoli estricnina, ingeri uma mistura sulfurosa de enxofre e ácido sulfúrico. Destruí meu fígado, os pulmões, os rins, a bílis, o cérebro, o coração, os intestinos. Ninguém sabe qual é minha doença. (HAŠEK: 2014, p. 72)

Ao contrário de Schlump, As aventuras do bom soldado Švejk não traz um humor leve, mas sim grotesco. O humor de Švejk denota os excessos do Estado e a impossibilidade de fugir dos horrores da guerra. A única forma de fugir da guerra seria causar a si mesmo danos físicos semelhantes aos que ela traria - ainda assim, o resultado final seria vantajoso, pois não contaria com o transtorno mental que é ironizado por Schlump.

Todavia, Grimm acreditava seu fracasso estava ligado ao desejo do público por algo realista, ou seja, não pelo picaresco, mas por um romance como Nada de novo no front. Eva Horn discute essa necessidade de representações da Primeira Guerra em um artigo sobre vivência e trauma. A pesquisadora afirma que aquilo que era buscado por homens que seguiam para a guerra até então era "uma [vivência] tripla: uma biográfica - a 'aventura' -, uma social - a 'vivência de coletividade' - e uma histórica - 'História mundial'." (HORN: 2000, p. 131) Com o advento da guerra moderna, a Primeira Guerra teria falhado em entregar qualquer experiência de vivência, e dela teria resultado, acima de tudo, o trauma, que é descrito por Horn como o oposto da vivência (Ibid.: 134; 139). Em situações de trauma, o indivíduo apresenta sérias dificuldades de reorganizar e narrar o ocorrido. Assim, Horn (Ibid.: 140) argumenta que as narrativas sobre a Primeira Guerra, publicadas na época imediatamente posterior aos fatos, vêm suprir a função de criar essa narrativa que os próprios sobreviventes não conseguiam tecer. Para Horn (Ibid. 143s.), um livro como Nada de novo no front não surge com a intenção de dar sentido à guerra - é uma obra justamente sobre a sua falta de sentido -, mas, ao reconstruir a guerra em forma de narrativa, ele estaria ajudando soldados a lidar com o próprio trauma, a criar a própria narrativa.

Schlump, de fato, não estava em condições de auxiliar ninguém a remontar narrativas, já que o que é descrito como a vivência do soldado é muito distante da realidade, havendo poucas exceções a essa regra. A falta de relação com a realidade pode mesmo ter sido a razão para o fracasso de Schlump em sua época, o que pouco tem a ver com o gênero no qual o romance se insere, visto o caso de As aventuras do bom soldado Švejk. Mesmo o romance picaresco tcheco consegue apresentar algo mais próximo da realidade, ou melhor, mais funcionalmente crítico, devido ao seu tratamento grotesco do assunto. O livro de Hašek não apenas teve uma boa recepção em sua época, mas ainda serviu de inspiração para Bertolt Brecht em uma peça que não se passava mais na Primeira, mas na Segunda Guerra: Schweyk im Zweiten Weltkrieg (Schweyk na Segunda Guerra). A peça, que não foi concluída em vida, mantém profundas semelhanças com o livro original, como a supracitada conversa entre doentes que discutem qual é a melhor forma de serem considerados inválidos para a guerra (BRECHT: 1967, p. 1970s.).

Se há uma característica dominante que fez que esse romance estivesse presente na lista negra, essa não é o pacifismo, mas a impertinência, que não é suficiente para criar uma 
obra pacifista exemplar. Schlump chega até mesmo a reproduzir o que podemos chamar de romantismo da guerra. Em pelo menos duas situações diferentes o soldado morto é justamente alguém que sofre por um amor frustrado ou impossível, e que se alistou justamente no desejo de morrer. Nada mais romântico do que se sacrificar na guerra por um amor não correspondido. Mas isso não é nada comparado à passagem na qual um colega de Schlump tem uma morte não apenas heroica, mas algo que nos dias de hoje pode até mesmo ser descrito como "cinematográfica":

Michel, ao lado dele, continuou o assalto. Nenhuma bala o atingia. Agora ele estava entre os Tommies [os americanos]. Com um golpe habilidoso, ele arrancou a espingarda da mão de um deles. Mas o que era isso? Ele joga sua espingarda longe e segura o Tommy com ambos os braços como se quisesse começar uma luta corporal. O Tommy era uma cabeça mais alto do que Michel e imensamente amplo. [...] Michel deve ter forças sobre-humanas. Ele pressiona o Tommy com o seu braço direito contra o seu peito. Agora ele tem o esquerdo livre. Ele arranca a granada de mão do cinto, granada modelo 24, e a rola entre ele e o inimigo. Ele o pressiona ainda mais forte contra o seu peito. Com os dentes, ele arranca a cabeça branca fora! Agora! Agora - ambos são feitos em pedaços! / Lá, onde eles haviam acabado de lutar, rola a cabeça de Michel. Ela fica de pé e olha para Schlump, os olhos completamente abertos, e parecia que ela queria sorrir. (GRIMM: 2014, p. 181)

Uma morte heróica e autoinfringida como essa, onde até mesmo o cadáver estaria mostrando a satisfação com o respectivo fim, não combina em nada com uma dita narrativa pacifista. Essa morte, inclusive, se apresenta não enquanto trauma, mas sim enquanto espetáculo que Schlump teve o privilégio de vivenciar. Ao buscar, acima de tudo, uma narrativa leve, o livro acaba se assemelhando com o discurso belicista mais do que o próprio autor aparentemente almejaria.

Até mesmo a representação das mulheres colabora para uma representação da guerra que não é tão distante da mistificação feita por aqueles que a defendem. Não é apenas a forma como o protagonista seduz e descarta as moças em suas andanças que é questionável. A apresentação de sua mãe e de Johanna, sua "escolhida", também são deveras problemáticas.

A mãe de Schlump é uma representação típica de progenitoras de soldados na guerra, no sentido de que ela se preocupa profundamente com o filho e faz sacrifícios para garantir o seu bem-estar. No romance, as descrições desse afeto costumam exagerar no sentimentalismo, o que não constitui o problema em si, mas sim o fato de que as preocupações com a guerra e com a sobrevivência são transferidas para a figura materna, e não se relacionam diretamente ao protagonista. Como quando Schlump se despede da mãe após uma visita: "Ele se despediu dela. Ela foi corajosa e não chorou. Ele brincou e riu para consolá-la. Na rua, ele se virou e acenou para ela mais uma vez. Ela tinha um lenço na mão e enxugava os olhos." (Ibid.: 135) O ato de não demonstrar preocupação é taxado de "corajoso", coragem que pode ser reconhecida em Schlump que se despede brincando. Mas a mãe não é realmente corajosa, ela apenas está escondendo seus sentimentos. Como Schlump está presente em 
poucas batalhas, ele apenas é representado como uma pessoa que sofre de um medo terrível da morte uma única vez (Ibid.: 189). Quando internado, a Schlump cabe a sensação de tédio (Ibid.: 215), a preocupação recai sobre sua mãe.

Mesmo ao final da guerra, o grande alívio pertence à mãe. O romance é encerrado com a seguinte frase: "Então eles [Schlump e Johanna] seguiram juntos para a casa de sua mãe, que neste momento não suspeitava que a hora mais feliz de sua vida havia chegado." (Ibid.: 333) É a hora mais feliz da vida da mãe, como se o próprio bem-estar não fosse um tema para o soldado. Se Schlump é malandro e impertinente durante a guerra, isso ocorre porque ele é mais esperto do que os outros, pois, como é afirmado por um terceiro em determinado momento, apenas os idiotas estão nas trincheiras (Ibid.: 158). Com esse tipo de narrativa não chega a haver um verdadeiro desmonte da imagem do soldado viril.

A mãe não é a única pessoa que se preocupa com Schlump, mas são sempre mulheres que tomam essa posição. Como quando ele deixa o vilarejo onde ficou inicialmente estacionado, a jovem Estelle se despede com gordas lágrimas nos olhos (Ibid.: 82), mas ele segue despreocupado. Ou Johanna, a moça em quem Schlump deu um beijo furtivo antes de partir para a guerra. Ela simplesmente não o esquece e, em meio à guerra, sentindo que ele estaria em apuros lhe escreve uma carta resignada, declarando seu amor, pedindo um sinal de vida e mais nada em troca (Ibid.: 206). A resposta de Schlump é breve e ele segue com suas diversas aventuras amorosas. É apenas quando o final da guerra se aproxima que o soldado entra em uma igreja, vê a imagem da Santa Joana D’Arc, fecha os olhos, e tem uma espécie de visão, na qual ele se recorda da guerra e vê que foi protegido todo o tempo pela santa, em cujo rosto ele reconhece a Johanna [Joana] que ele deixou para trás. A partir deste momento, Schlump passa a frequentar a igreja para admirar a imagem da santa, e finalmente volta a escrever para a moça, desta vez para declarar o seu amor sincero.

Essa "visão" indica que o soldado, de fato, não haveria tomado conhecimento dos riscos quando esteve em batalha. Também é interessante notar que ele associa a (a partir de então) mulher amada a uma santa virgem. Após se refestelar, inclusive deixando uma moça grávida para trás, Schlump está pronto para voltar para casa para os braços daquela que se manteve pura enquanto esperava por ele. Mas Johanna é mais do que uma representação da típica "mulher para casar". Esse desfecho se relaciona, em certo grau, à obra inspiradora de Schlump: O aventuroso Simplicissimus. Como mencionado anteriormente, as diversas aventuras de Simplicissimus são o longo caminho que ele percorre até se converter ao catolicismo tornando-se um homem pio, dedicado a Deus. Ao identificar Johanna com uma santa, Schlump também teria encontrado sua salvação, tanto que ao reencontrar a moça no momento de sua chegada de trem, o narrador ainda se refere a ela como santa: "E abaixo, nos degraus diante da entrada, lá estava alguém de pé. A santa Joana. Schlump correu até ela: 'Como você sabia?' Ela olhou feliz para ele. 'Eu esperei por você todos os dias', ela disse”. (GRIMM: 2014, p. 333) A história de Schlump é encerrada em seu encontro com uma figura supostamente santa. Reconhece-se aqui uma mímica dos primeiros romances picarescos. Uma mímica da conversão. Mas, como é típico desta obra, isso não resulta de complexas experiências que levam o protagonista a um conhecimento mais nobre. Em $O$ aventuroso Simplicissimus, o protagonista perde a beleza de forma definitiva após contrair uma doença 
venérea através suas aventuras carnais. Toda sua fortuna também se esvai. Não há honra ou glória que perdure. Já em Schlump, é como se sua "inocência" fosse um bem maior. As mulheres com quem se envolve lhe enviam pacotes fartos em guloseimas em plena época de fome (Ibid.: 133). Ele é salvo de maiores ferimentos por uma força celestial, como se fosse o próprio escolhido. E ao retornar, mais uma vez, não há sacrifício que o aguarde, e sim uma mãe dedicada e uma futura esposa fiel, que são a garantia de um brando recomeço em seu retorno ao lar.

Schlump, de fato, apresenta as batalhas como algo cruel, questiona hierarquias e a subserviência, além de apresentar os franceses como um povo cordial, mas, para uma obra pacifista, falta o aspecto esclarecedor sobre a realidade da guerra. Mortes heroicas ou românticas, o "corpo fechado" de Schlump associado às aventuras amorosas e a contração de diversas vivências (aquelas que Horn considera negadas a pessoas que sofreram de traumas), assim como a garantia de um recomeço pleno e tranquilo, são características que enfraquecem qualquer questionamento à guerra. Desse ponto de vista, a guerra parece continuar sendo uma experiência válida para "homens fortes" que tenham convicção em suas finalidades. Ou algo que possa ser contornado desde que se tenha a esperteza ou a sorte de um Schlump.

Como mencionado anteriormente, os críticos notaram essas mazelas. Weidermann chega até mesmo a escrever que "É fácil subestimar esse livro. Na verdade, ele chega até mesmo a nos convidar a fazê-lo." (WEIDERMANN: 2014, p. 340) Uma pena que críticos experientes não tenham aceitado o convite. O desejo de ser um dos heróis responsáveis pela reparação de males ocasionados por nazistas falou mais alto. O preço dessa reparação foi o elogio de uma obra de qualidades duvidosas já em sua própria época: Schlump teve uma recepção limitada, por ser um tipo de retrato da guerra que não condizia com as duras experiências e os anseios daqueles que estiveram de alguma forma envolvidos. Não é de impressionar que tenha sido ofuscado pelos tons mais realistas e sombrios de outros títulos lançados no mesmo ano, como Nada de novo no front.

\section{REFERÊNCIAS BIBLIOGRÁFICAS}

BRECHT, Bertolt. “Schweyk im Zweiten Weltkrieg.” In: BRECHT, Bertolt. Stücke 5. Frankfurt am Main: Suhrkamp Verlag, 1967, p. 1913-1997.

GRIMM, Hans Herbert. Schlump. Köln: Kiepenheuer \& Witsch, 2014.

GRIMMELSHAUSEN, Hans Jacob Christoffel. O aventuroso Simplicissimus. Trad.: Mario Luiz Frungillo. Curitiba: Ed. UFPR, 2008.

HAŠEK, Jaroslav. As aventuras do bom soldado Švejk. Trad.: Luís Carlos Cabral. Rio de Janeiro: Objetiva, 2014.

HORN, Eva. "Erlebnis und Trauma. Die narrative Konstruktion des Ereignisses in Psychiatrie und 
Kriegsroman.” In: MÜLDER-BACH, Inka. Modernität und Trauma. Wien: WUV, 2000, p. 131-162.

KÜRTEN, Jochen. "Schlump: Eine literarische Wiederentdeckung." Deutsche Welle Online. 24 de junho de 2014 https://www.dw.com/de/schlump-eine-literarische-wiederentdeckung/a-17729754 Acesso em 29/01/2019.

JACOBS, Jürgen. Der deutsche Schelmenroman. Eine Einführung. München; Zürich: Artemis Verlag, 1983.

__- “Schelmenroman.” In: MÜLLER, Jan-Dirk (org.) Reallexikon der deutschen Literaturwissenschaft. Band III. P-Z. Berlin; New York: Walter de Gruyter, 2007, p. 371-374.

LIU, Max. "Schlump by Hans Herbert Grimm, book review”. The Independent. 16 de abril de 2015. https://www.independent.co.uk/arts-entertainment/books/reviews/schlump-by-hans-herbert-grimmbook-review-10181522.html Acesso em 29/01/2019.

RÜHMKORF, Peter. "Nach dem Soergel der Serke. Kein Wiedergutmachungs-, sondern ein Wiederentdeckungsbuch.” Die Zeit. 10 de fevereiro de 1978 https://www.zeit.de/1978/07/nach-demsoergel-der-serke Acesso em 18/01/2019.

SCHIMMANG, Jochen. "Nicht nur Dumme kommen in die Schützengräben". Frankfurter Allgemeine Zeitung. 25 de abril de 2014. https://www.faz.net/aktuell/feuilleton/buecher/nicht-nurdumme-kommen-in-die-schuetzengraeben-hans-herrmann-grimm-grosser-weltkriegsromanschlump-12910285.html Acesso em 29/01/2019.

WEIDERMANN, Volker. “Nachwort.” In: GRIMM, Hans Herbert. Schlump. Köln: Kiepenheuer \& Witsch, 2014, p. 335-348.

. Das Buch der verbrannten Bücher. Köln: Kiepenheuer \& Witsch, 2008. 
